\title{
Metal-organic complexes as a major sink for rare earth elements in soils
}

\author{
Fedotov P.S. ${ }^{1,2}$, Rogova O.B. ${ }^{3}$, Dzhenloda R.Kh. ${ }^{1,2}$, Karandashev V.K. ${ }^{1,4}$ \\ ${ }^{1}$ National University of Science and Technology "MISiS", 4 Leninsky Prospect, Moscow 119049, \\ Russia \\ ${ }^{2}$ Vernadsky Institute of Geochemistry and Analytical Chemistry, Russian Academy of Sciences, 19 \\ Kosygin Street, Moscow 119991, Russia \\ ${ }^{3}$ Dokuchaev Soil Science Institute, 7 bld 2 Pyzhevskiy Per, Moscow 119017, Russia \\ ${ }^{4}$ The Institute of Microelectronics Technology and High-Purity Materials, Russian Academy of \\ Sciences, 6 Institution Street, Chernogolovka 142432, Russia
}

doi: 10.36291/HIT.2019.fedotov.027

The role of rare earth elements (REEs) in soil-plant systems has attracted an increasing attention but still remains somewhat unclear. Apart from in-vivo studies on the uptake of REEs by plants, in-vitro chemical fractionation of REEs in soil according to their physicochemical mobility can offer additional insights into the behavior of REEs. In the present work the fractionation of REEs has been studied by the example of background, aerially and hydrogenically contaminated soil samples using dynamic (continuous flow) extraction, which allows one to mimic natural conditions and minimize artefacts. The eluents applied addressed exchangeable, specifically sorbed, bound to Mn oxides, bound to metal-organic complexes, and bound to amorphous and poorly ordered Fe/Al oxides fractions extractable by $0.05 \mathrm{M} \mathrm{Ca}\left(\mathrm{NO}_{3}\right)_{2}, 0.43 \mathrm{M} \mathrm{CH}_{3} \mathrm{COOH}, 0.1 \mathrm{M} \mathrm{NH} \mathrm{NH}_{2} \mathrm{OH} \cdot \mathrm{HCl}, 0.1 \mathrm{M}$ $\mathrm{K}_{4} \mathrm{P}_{2} \mathrm{O}_{7}$ at $\mathrm{pH} 11$, and $0.1 \mathrm{M}\left(\mathrm{NH}_{4}\right)_{2} \mathrm{C}_{2} \mathrm{O}_{4}$ at $\mathrm{pH} 3.2$, respectively. The distribution of trace metals (such as $\mathrm{Pb}, \mathrm{Cu}, \mathrm{Zn}, \mathrm{Ni}$ ) between separated fractions varies with sample and is dependent on the type of contamination. However, for all studied samples, the recoveries of REEs by pyrophosphate are surprisingly high, up to $40-45 \%$ of their total concentrations in background and anthropogenic transformed floodplain soils. The contents of REEs bound to $\mathrm{Fe} / \mathrm{Al}$ oxides are relatively low, no more than $12 \%$. REEs in other fractions may be taken into consideration only for aerially contaminated soil. To the best of our knowledge, such predominant association of REEs and metal-organic complexes (e.g. humic and fulvic compounds) independently on the type of soil has not been reported before.

To the best of our knowledge, the predominant association of REEs and metalorganic complexes in soils regardless the sample type and contamination is reported for the first time. This finding may offer a novel insight into the fate and behavior of REEs in soil-plant systems. The results should be extended to a variety of soil samples of different origin. Besides, it may be beneficial to apply another SEP (Mittermüller et al, 2016) under dynamic conditions and to compare the data obtained.

For the risk assessment, it would extremely important to study processes of adaptation of REEs entering the soil with various carriers such as phosphorus fertilizers, coal and phosphate dust, industrial wastes, etc.

Acknowledgements. The authors would like to acknowledge the financial support from the Russian Science Foundation (project No 16-13-10417). The equipment was purchased and maintained with the support of the Ministry of Education and Science of the Russian Federation (Program of Increasing Competitiveness of NUST "MISiS", projects No K1-2014-026, No K2-2017-088). 